Y 3.A.7

$221 K-15-86 \quad$ RESEARCH REPORTS
AEC RESEARCH AND DEVELOPMENT REPORT

AUTHORS:

R. H. Stevens

R. C. Smith

UNIVERSITY
ARIT ARIZON.

ARIZONA LIB.NAR .

Documents Collection

JUN 111964

\title{
A PORTABLE NEUTRON COUNTER FOR DETERMINING WEIGHTS OF DEPOSITS OF URANIUM-FLUORINE COMPOUNDS
}

\section{UNION CARBIDE}

UNION CARBDE CORPORATION NUOLEAR DIVISION

\section{Operating the}

OAK RIDGE GASEOUS DIFFUSION PLANT OAK RIDGE Y.12 PLANT

For the Aromic Energy Commission Under U.S. Government Contraci W7 405 eng 26
- oAK RIDGE national LABORATORY

- PADUCAH GasEOUS DIFFUSION PLANT 

Date of Issue: May 11, 1964

Report Number: $\mathrm{K}-1586$

Subject Category: INSTRUMENTS

(TID 4500, 28th Ed.)

A PORTABLE NEUTRON COUNTER FOR DETERMINING WEIGHTS OF DEPOSITS OF URANIUM-FLUORINE COMPOUNDS

R. H. Stevens and R. C. Smith

Technical Division

Instrument Development Department

UNION CARBIDE CORPORATION

NUCLEAR DIVISION

Oak Ridge Gaseous Diffusion Plant

Oak Ridge, Tennessee 

Report Number: $\mathrm{K}-1586$

Subject Category: INSTRUMENTS

Title: A PORTABIE NEUTRON COUNTER FOR DETERMINING WEIGHTS OF DEPOSITS OF URANIUM-FLUORINE COMPOUNDS

Authors: R. H. Stevens and R. C. Smith

$\underline{A} \underline{B} \underline{\mathrm{S}} \underline{\mathrm{T}} \underline{\mathrm{R}} \underline{\mathrm{A}} \underline{\mathrm{C}} \underline{\mathrm{T}}$

A high sensitivity, portable fast neutron counter has been developed for determining the weights of solid accumulations of uranium-fluorine compounds in closed process equipment. The instrument is sensitive to neutron flux as low as 0.005 neutrons per square centimeter per second, which is about $0.02 \%$ of the maximum permissible fast neutron dose rate for man. The neutron flux from the deposits in plant equipment results from the reaction between alpha particles emitted by the decaying uranium and fluorine nuclei, and is thus a function of the amount of uranium present. Although special techniques are necessary for the evaluation of the data obtained with the neutron counter, results are much more reliable than those depending on measurements of gamma radiation intensities which are seriously affected by the shielding effects of process equipment, self-absorption of thick uranium deposits, and by the presence of uranium daughter products. The neutron counter consists of a moderated boron trifluoride-filled ionization chamber probe and a battery powered scaling unit interconnected by a 35 foot cable. The instrument will operate five to eleven hours, depending on the counting rate, before battery recharging is necessary. The construction of the instrument, the techniques used in monitoring deposits, and the evaluation of neutron count data to obtain weight estimates are described. 

A PORTABLE NEUTRON COUNTER FOR DETERMINING WEIGHTS OF DEPOSITS OF URANIUM-FLUORINE COMPOUNDS

TABLE OF CONTENTS

INTRODUCTION- - 7

DESCRIPTION OF THE NEUTRON COUNTER-

PRINCIPIES OF OPERATION OF THE NEUTRON MONITOR-_.

Required Properties of the Monitor-....... 9

Essential Characteristics of the Probe-.................. 10

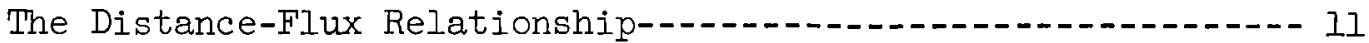

The Dependence of Neutron Emission Upon the

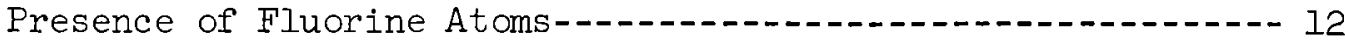

The Effect of Assay on Neutron Flux-12

Other Factors Affecting Neutron Flux at

a Distance from the Source-1...- 12

PROCEDURES FOR USING THE COUNTER IN ESTIMATING DEPOSIT WEIGHTS----- 13

Probe Sensitivity Measurement-1-1-0.-13

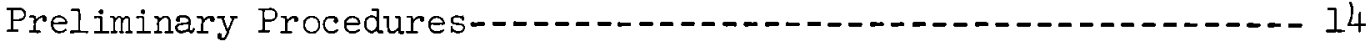

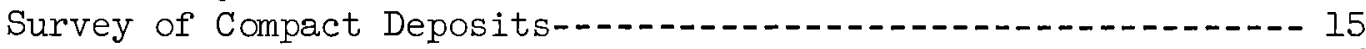

Survey of Distributed Deposits-1...-16

UNCERTAINTIES IN WEIGHT ESTIMATES-

Distance Error-1-10 16

Assay Error-1.- 17

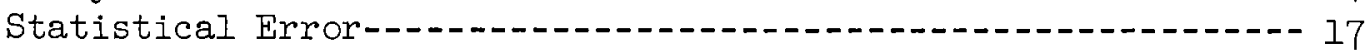

Total Error-..-...... 17

EXAMPLES OF DEPOSIT WEIGHT ESTIMATES

ACKNOWIEDGEMENTS-

BIBLIOGRAPHY

ILIUSTRATIONS- 

A PORTABLE NEUTRON COUNTER FOR DETERMINING WEIGHTS OF DEPOSITS OF URANIUM-FLUORINE COMPOUNDS

\section{INTRODUCTION}

In a gaseous diffusion plant conditions may occasionally occur which lead to the deposition in plant equipment of uranium compounds in the solid phase. For example, moist air inleakage results in the formation of $\mathrm{UO}_{2} \mathrm{~F}_{2}$; heater failure may allow UF6 to condense in a valve, pipe line or other container; other equipment failure might lead to increased temperatures at some points, forming UF'4. Such deposits must be located and the conditions causing their formation corrected to prevent radiation hazards and to simplify inventory problems. Visual inspection is not possible since these deposits are formed within closed equipment. A probe incorporating an ionization chamber filled with argon or xenon is useful in locating these accumulations, but such an instrument has serious limitations for use in estimating the weight of a deposit. The neutron monitor yields information from which can be obtained a valid and more precise determination of the amount of uranium salt that may be accumulated at a particular location in the operating plant.

Since the natural decay of uranium is accompanied by gamma radiation emission, an argon-filled ionization probe responds to the presence of uranium, and the high sensitivity of this probe makes possible the rapid surveying of equipment; however, the intensity of gamma radiation cannot be reliably related to the quantity of a uranium accumulation for several reasons. A large part of this gamma radiation is absorbed by process equipment, usually steel and aluminum, between the deposit and the probe, and this shielding material may rarely be assumed to have the same thickness and gamma opaqueness on all sides of the deposit. Thus, it is quite difficult to ascertain the quantitative effects of this shielding on the intensity of gamma radiation at the probe. Also, since a layer of uranium salt one quarter inch thick will almost completely absorb any gamma rays originating behind it, the signal from the probe is little different whether the thickness of the deposit is one quarter inch or several inches. The decay of uranium also produces some daughter products that are more gamma active than the parent; it is possible that there may be a higher gamma emission from an old deposit containing these daughters than from a new deposit of equal or greater weight. If the uranium is revaporized, the non-volatile daughters inside the deposit may be less shielded than before revaporization and the gamma intensity may increase even though less uranium be present.

The presence of chemically combined fluorine in uranium salts provides a mechanism by which a quantitative measurement of the uranium can be obtained. This is the alpha-neutron reaction which occurs when an alpha particle, emitted by a decaying uranium atom, is absorbed by a fluorine nucleus to produce a fast neutron (energy, 4 to 6 mev.): 


$$
9^{\mathrm{F}^{19}}+2^{\mathrm{He}^{4}} \rightarrow \mathrm{O}^{\mathrm{n}}+{ }_{11} \mathrm{Na}^{22}
$$

The number of neutrons per second emanating from a mass of a uraniumfluorine compound does bear a quantitative relationship to the amount of uranium present, and it is this neutron flux which the monitor is designed to measure.

Fast neutrons pass easily through materials of construction, such as steel, aluminum, nickel, or monel, with little loss of energy. They do lose energy, however, and may be absorbed by atoms of light elements in passing through hydrogeneous materials such as lucite, polyethylene, paraffin, water, oils, or the human body. These materials, however, are not common in the plant system.

The instrument described here was designed to be sensitive to neutrons but not to gamma radiation so that uranium deposit weights could be determined from its response. The techniques developed for the use of the instrument make such determinations feasible.

\section{DESCRIPTION OF THE NEUTRON COUNTER}

The neutron monitor consists of a probe connected by a 35-foot shielded cable to a case enclosing batteries, a scaler and other electronic circuitry. The size of the instrument is represented in figure l, which portrays the equipment ready for use and the detachable battery charger. The total weight of the probe and scaler is 36 pounds, of which 22 pounds are in the probe.

The probe container includes a thick-walled cylindrical paraffin moderator surrounding a slow neutron counter tube. This counter tube is filled with 96 per cent B-10 enriched boron trifluoride at $40 \mathrm{~cm}$. $\mathrm{Hg}$. pressure; its active length is twelve inches and its diameter, two inches. Figure 2 shows the cover removed from the probe. The end of the counter tube may be seen protruding from the paraffin moderator and above this is the three inch thick plastic foam cap which houses the thermally insulated preamplifier. The probe is designed to withstand exposure for several hours to a temperature of $180^{\circ} \mathrm{F}$. and to $125^{\circ} \mathrm{F}$. continuously. Figure 3 depicts a cross-section of the probe. For greatest sensitivity, the thickness of the walls of the moderator should be about three inches and the earlier model of the probe did utilize this much paraffin. However, the weight and size of this model of the probe made it unwieldy and, to facilitate its use, the thickness of the paraffin was decreased to about 1-3/4 inches. The number of events counted was reduced about 30 per cent in the revised design which thus represents a compromise between weight and sensitivity. 
The scaler utilizes solid state circuitry throughout. Figure 4 is a schematic diagram of the circuit showing the two amplifier stages, a pulse inverter, a decade scaler, a one-shot multivibrator for shaping the scaler output waveform, and a relay driver power stage for supplying a fast high-current pulse to actuate the mechanical register. A 3.8 millivolt pulse is required from the counter tube to register a single count on the scaler. The speed of the circuit is such that it can count evenly spaced pulses at the maximum rate of approximately 4000 per minute. A blocking grid oscillator type high voltage supply provides 2500 volts to operate the counter tube. A decade reset button, when depressed, returns the decade reading to zero and can be used for short periods to stop the count and permit resetting the register before starting a new count in high flux fields.

The input capacitor (figures $2,3,4$ ) requires special attention. A guard ring at each end is needed to prevent surface leakage due to moisture from introducing spurious counts into the input circuit. The ring at the probe end of the condenser is connected to the positive side of the high voltage supply; the ring at the amplifier end of the condenser is grounded.

Four 7.2-volt nickel-cadmium batteries in the scaler case furnish power for the circuitry. Shunt resistors across each battery are used to adjust the individual discharge rates to a common value of about 130 milliamperes, providing from eleven to five hours of continuous operation from one full charge at counting rates of from ten to 2000 per minute, respectively. The fast charge rate of the detachable charger supplied with the instrument is such that the recharge time required is approximately equal to the total operating time of the instrument since the last prior charge. A timer on the charger is adjusted to provide a fast charging rate for a preset period, after which the rate is decreased to a trickle charge value of about ten milliamperes. The battery charge condition is indicated on a meter on the front panel. Figure 5 shows the internal construction of the scaler unit.

The feasibility of using a phosphor-filled plastic scintillator for neutron detection was also investigated. Tests were made using a plastic disc containing boron-10 and $\operatorname{ZnS}(\mathrm{Ag})$, but because of the apparent low efficiency and small intercepting area this method was rejected.

\section{PRINCIPLES OF OPERATION OF THE NEUTRON MONITOR}

Required Properties of the Monitor

Neutron sensitive survey meters are commercially available for health physics applications, but these are several orders of magnitude too insensitive for use in estimating deposit sizes. For example, the neutron flux at one foot distance from four pounds of UF 6 of 1 per cent U-235 assay is about 1/10,000 of the allowable fast neutron dose rate for a man having 40 hours per week exposure. At 95 per cent U-235 assay, four pounds produces a flux of only about $1 / 100$ this allowable 
dose rate. It is because the magnitude of the neutron flux from deposits of interest is so small that a more sensitive monitor was required.

Also, because this neutron flux is small compared to the gamma flux, the preliminary surveys are made with a gamma sensitive probe. For example, the gamma radiation field one foot from a typical small deposit of natural uranium combined as the oxyfluoride would be in the order of 0.3 milliroentgens per hour. This rate is easily monitored by most commercial gamma sensitive instruments. The fast neutron flux from this same deposit would be of the order of 0.005 neutrons per square centimeter per second, or about 0.02 per cent of the permissible fast ( 4 mev.) neutron dose rate for man, assuming a $5 \mathrm{rem}$. per year dose average over a 2000 hour work year (1).

Because of the paucity of neutrons arriving at the probe from a deposit, and since it is not possible to read very small neutron flux values from a rate-type instrument, the monitor necessarily must possess the attributes of a counter. Neutrons arrive at the detector in a random manner and must be counted over a time interval sufficient to reduce the inherent statistical error to an acceptable value. And because of the effects of neutron scattering, attenuation with distance, differing geometries, sizes and distributions of deposits and background neutron flux, the estimation of a single deposit requires counting neutrons at several locations in the vicinity of the deposit. The interpretation of these counts, and from them making an estimate of deposit size, involves techniques developed by experience; these are described in a later section.

\section{Essential Characteristics of the Probe}

The function of the probe is to interrupt fast neutrons and to sense these events in some way that they may be counted. Since it is easier to make a sufficiently sensitive detector for slow neutrons than for fast ones, the probe includes a moderator for reducing the energy of the fast neutrons before they reach the detector. This is the purpose of the layer of paraffin around the boron trifluoride gas filled counter tube. This tube is sensitive to thermal neutrons which are detected when they are captured by atoms of B-10 according to the nuclear reaction:

$$
5^{\mathrm{B}^{10}}+\mathrm{O}^{\mathrm{n}} \rightarrow 2^{\mathrm{He}^{4}}+{ }_{3}^{\mathrm{Li}^{7}}
$$

The alpha particles so produced ionize gas molecules in the tube which is a proportional counter. A voltage pulse appears at the preamplifier input for each captured neutron. The size of this pulse is proportional to the number of ions produced initially by the alpha particle and is usually between 0.003 and 0.008 volt. Each such pulse is amplified and registered in the instrument as a single event and neutron flux is measured by counting the number of such events that occur in a given 
time. The process is depicted diagrammatically in figure 6 .

Because the counter tube is a long cylinder, the number of neutrons it can intercept depends upon its orientation with respect to the neutron field. Reproducible measurements of neutron flux can be made only if the probe is placed in the same position relative to the direction of the deposit for each measurement. Greatest sensitivity is obtained when the probe axis is perpendicular to the line between deposit and probe.

The Distance-Flux Relationship

It might be expected that the measured value of neutron flux would vary with the distance between the source and the probe according to the inverse square law, and this expectation is realized approximately under certain conditions, as is illustrated in figure 7 . These data were obtained using a plutonium-beryllium source, the total flux from which was $5 \times 10^{5}$ fast neutrons per second. In this case, the paraffin moderator surrounding the counter tube was 3 inches thick. The source was placed 12 inches above a cement floor and the probe center was at the same height. Distances between the source and the probe were always measured from the effective center of the source to the midpoint of the axis of the probe. The effective center of the spatially small Pu-Be source was assumed to coincide with the geometrical center.

In the use of the neutron monitor for estimating the sizes of deposits, the probe necessarily has to be placed at different distances from the deposit as determined by the size and configuration of the equipment being monitored. These deposits frequently are spatially large and neutron reflecting surfaces may be oriented in various ways with respect to the source. Under such conditions the flux has been observed to vary approximately as the inverse 1.6 power of the distance. Thus, it becomes necessary to obtain a flux-distance function applicable to conditions under which the monitor is used.

A set of calibration curves, figure 8 , based on measurements made with the monitor of the neutron flux from samples of known composition and assay at known distances were compiled for use in plant monitoring problems. The probe was equipped with the final design moderator which has a paraffin thickness of $1-3 / 4$ inches. Because of the diverse natures of these problems, there is no rigorous solution applicable to all. In obtaining the data for the calibration curves, containers of known weights and assays of uranium hexafluoride were suspended two feet above a concrete floor and the probe was placed at the same height at various distances. The $\mathrm{UF}_{6}$ containers were cylinders about two feet long and five inches in diameter. These cylinders and the probe were always oriented during a count with their axes vertical. It was hypothesized that these conditions would simulate those to be found in the plant, insofar as neutron reflection, absorption, and scattering affect the distance-flux relationship. Results of deposit measurements that could be verified have indicated that the curves are adequate and valid. 
The Dependence of Neutron Emission Upon the Presence of Fluorine Atoms

It has already been mentioned that the neutrons emitted from an accumulation of uranium salts in process equipment originate from a reaction between fluorine nuclei and alpha particles. Thus, the neutron flux from such a deposit will depend upon the availability of fluorine atoms as well as upon the emission of alpha particles (from decaying uranium). Hence, the neutron flux from one uraniumfluorine compound will differ from that from another having a different uranium-fluorine ratio.

Although data for the calibration curves were obtained from measurements on uranium hexafluoride samples, the curves, for convenience, are drawn for the oxyfluoride; when deposits of the hexafluoride or the tetrafluoride are measured, the neutron activity ratios are used. These ratios were established by using samples of these salts in comparative measurements. If the activity of a certain amount and assay of a uraniumfluorine compound is represented by $A\left(U_{i} F_{j}\right)$, then by measurement:

$$
\mathrm{A}\left(\mathrm{UO}_{2} \mathrm{~F}_{2}\right): \mathrm{A}\left(\mathrm{UF}_{4}\right): \mathrm{A}\left(\mathrm{UF}_{6}\right):: 1: 1.28: 1.76
$$

It should also be noted that some other nuclei than fluorine emit neutrons by absorption of alpha particles (2). In fact, some, e.g., beryllium and boron, are more efficient at this than fluorine. But of these which do react in this way with alpha particles, only aluminum and oxygen may be expected to be present in process deposits, and these are about 15 and 150 times less efficient, respectively, than fluorine in producing neutrons. Aluminum is present infrequently and the oxygen contribution is negligible.

\section{The Effect of Assay on Neutron Flux}

The several isotopes of uranium have different alpha activities; thus, the neutron flux is also a function of assay, and the activity of any process sample depends on the distribution of the alpha-active isotopes. It might be assumed that a knowledge of this distribution for each deposit monitored would be required. However, it is fortuitous, from the point of view of the neutron monitor calibration problem, that the total alpha activity of process material is approximately a linear function of U-235 assay value. Since the calibration curves in figure 8 were determined by measurements made on samples from the plant process, the effects of the contributions from all the various uranium isotopes are included in the calibrations.

Other Factors Affecting Neutron Flux at a Distance from the Source

The attenuation of gamma radiation by construction materials, e.g., steel, makes the gamma sensitive probe unsuitable for use in estimating deposit sizes, but because these materials do not appreciably hinder the passage of neutrons, the neutron monitor does not have this 
disadvantage. However, neutrons are reflected, scattered, slowed or absorbed by some materials. That they are thermalized or slowed by atoms of low atomic weight as in the moderator and are then absorbed by boron atoms in a counter tube with the emission of alpha particles, makes this neutron counter possible. Nevertheless, these same materials, which may be located inadvertently between the deposit and the probe, may also prevent the monitor from yielding the data needed to obtain a reasonable estimate of deposit size. Fortunately, hydrogeneous materials are not usually encountered in process equipment, but it should be ascertained that such items as tanks of water or oil, blocks of concrete, or organic materials (e.g., the man making the observations) are not located between the deposit and probe, or are not so placed that they might act as reflectors behind the deposit or the probe.

The measured value of the flux is also affected by the state and the compactness of the salt. For, while it may be assumed that a compact mass of solid UF produces approximately the same number of neutrons as the same weight of gaseous $\mathrm{UF}_{6}$, the volume of the gas so greatly exceeds the volume of the solid that the neutrons escape the gas over a much larger area. Therefore, when the probe is near the source, the flux contribution at the probe of neutrons originating in the gas is much less than that from the solid. Since it is the amount of solid that is of primary concern when monitoring process equipment, the contribution from the gas is usually included in neutron flux background measurements.

\section{PROCEDURES FOR USING THE COUNTER IN ESTIMATING DEPOSIT WEIGHTS}

\section{Probe Sensitivity Measurement}

It is advisable to check the sensitivity periodically. Small variations may occur because of environmental changes outside the instrument; these are unavoidable but relatively unimportant. The periodic checks are valuable in effecting preventative maintenance and to help ensure that all components are in satisfactory working order.

For making these comparison sensitivity checks, standard conditions have been chosen, as follows:

Source: Pu-Be, $3.49 \times 10^{6}$ neutrons per second.

Probe Orientation: Axis vertical

Height of Probe Base Above Concrete Floor: 48 inches

Source Height Above Concrete Floor: 57 inches

Source to Probe Distance: 20 feet

The calibration curves of figure 8 apply when the sensitivity factor is unity; arbitrarily, this situation is defined to exist when the net count is 694 events per minute. Although it is not feasible to obtain calibration curves applicable to every possible arrangement of source, probe and reflectors, the observations made using the same source and probe and listed in table I illustrate the effects of changing the arrangement. 
TABLE I

NET COUNTS FOR THREE PROBE-SOURCE CONFIGURATIONS

\begin{tabular}{|c|c|c|c|}
\hline \multirow{2}{*}{$\begin{array}{c}\text { Probe-Source } \\
\text { Distance } \\
\text { Ft. }\end{array}$} & \multicolumn{3}{|c|}{ EVENTS PER MINUTE } \\
\cline { 2 - 4 } & I Ft. $^{\mathrm{a}}$ & $4-3 / 4 \mathrm{Ft}^{\mathrm{a}}$ & 16 Ft. \\
\hline 10 & 2420 & 2518 & 1950 \\
20 & 758 & $694^{\mathrm{c}}$ & 540 \\
30 & 268 & 317 & 270 \\
\hline $\begin{array}{l}\text { Ratio: } \\
10 \text { Ft./20 Ft. }\end{array}$ & 3.19 & 3.64 & 3.75 \\
\hline $\begin{array}{l}\text { aver Concrete } \\
\text { b Over Earth and Crushed Rock } \\
\text { C Arbitrary Standard Used for Checking Source }\end{array}$ & \\
\hline
\end{tabular}

Preliminary Procedures

Since the use of the neutron monitor requires counting, which is a timeconsuming technique, deposits in equipment are first located with a garma sensitive argon or xenon probe. It is after a region of high gamma radiation is found that the neutron flux from the suspected equipment or region is measured at several points around the equipment, and it is from these data and other information that size and weight estimates are made. The needed other information includes the assay of the deposit, its chemical form, and whether any large amount of HF is present in the solid.

For a new deposit, the assay may be assumed to be that associated with the location in the plant; the assay of an old deposit may be taken as the average of assay values for the plant location over the period corresponding to the age of the deposit. The age may be estimated from the history of gamma surveys at the location. From an old deposit the greater part of the gamma activity may be attributed to uranium daughter products. The probable chemical form may be inferred from a knowledge of the process as it applies to the location of the deposit. For example, a wet air leak would lead to the formation of the oxyfluoride. An abnormally low temperature at some point in the process could result in solidification of the hexafluoride, and an abnormally high temperature might cause the formation of deposits of the tetrafluoride. 
To determine the mass of an accumulation from the calibration curve (figure 8), the neutron flux at some particular distance must be counted for a measured time. Knowing the distance from probe to deposit requires knowing the location of the effective center of the deposit, and the preferred technique for finding this center is not the same for all cases. To simplify this problem, two classes of deposits may be considered: compact and distributed. If the flux gradient, as the probe is moved around the deposit, is everywhere small so that the limits of the deposit are poorly defined, it may be assumed that the accumulation is diffuse, and is probably distributed in thin layers over the inner surfaces of the equipment. If large changes in flux are observed as the probe is moved slowly around the equipment being monitored, the deposit probably is in the form of a compact mass. The garma probe may be useful in helping determine the limits of the accumulation, but the possibility of the presence of uranium daughter products and of unknown shielding thicknesses necessitates verification by neutron flux measurements. These measurements are taken at several locations about the equipment and a point is chosen as the effective center consistent with the results of the measurements. In this, experience plays a major role and most of the developmental work on data interpretation has been spent in this phase of the problem.

\section{Survey of Compact Deposits}

When the uranium salt is deposited in a compact lump, such as frequently occurs at a point of slow inleakage of moist air, the center of the accumulation is easily located. A typical example is as follows: consider a valve in which three pounds of $\mathrm{UO}_{2} \mathrm{~F}_{2}$ at an assay of 30 per cent U-235 are localized on the seal. This Situation is illustrated in figure 9. The location of the largest gamma radiation measurement is on one side of the valve, about half way up the valve body. With the neutron counter probe at the eight positions shown, measurements of the neutron flux are made and the location of the deposit is inferred. In this example, the upper four locations indicate about twice the flux on the front side as on the rear, and the values on the two sides are the same. The same trend is observed in the readings from the four bottom positions. The values indicated are typical net readings in counts per minute using the neutron monitor. To obtain the net deposit count, a neutron background reading resulting from the $\mathrm{UF}_{6}$ gas nearby must be subtracted from the gross count. The background is obtained by counting neutrons at an identical clean valve at an adjacent process location having nearly the same gas pressure and assay.

Inasmuch as the readings at the upper and lower front positions in figure 9 are nearly the same, it is inferred that the deposit is midway between these positions. Since a leak through the valve wall is improbable, it may be assumed that the $\mathrm{UO}_{2} \mathrm{~F}_{2}$ accumulation is probably in lump form and attached to the seal. From known valve dimensions, the distance from the wall to the deposit is estimated. For a final count the probe is placed at the same height as the estimated position of the deposit and twelve inches from it. The final count typically requires about 15 minutes for 1000 events. From this count rate is 
subtracted the background count rate to obtain the value used with the calibration curve in determining the estimated weight. Estimated weights of compact deposits are usually within $\pm 25 \%$ of the recovered weight values.

\section{Survey of Distributed Deposits}

A method of calculating the weight of a uniformly distributed deposit of $\mathrm{UF}_{4}$ is illustrated in figure 10. Here, it is assumed that a heat exchanger contains $\mathrm{UF}_{4}$ powder and that all tubes are approximately equally filled. Gamma survey readings show a uniform gamma field level over the entire exterior. The neutron monitor can be used to survey the deposit and confirm the uniformity of distribution. For the gross count, the neutron probe is placed about one foot distant from the outer shell of the exchanger. A background reading may be taken on another identical heat exchanger under similar process conditions, or, if the exchanger is to be removed from process, the location may be monitored after the removal to obtain a background reading.

A "mock distribution" method of calculating the weight of a distributed deposit has been developed. An array of lumped deposits arranged as shown in figure 10 is postulated, and the total effect of all these Iumps on the detector probe can be calculated for one position of the probe used in making the original measurement. The values of the calculated probe reading and the measured reading are compared; if they do not agree, a modified array is assumed for new calculations. This reiterative method is used until the calculated and measured readings agree within reasonable limits, in which case the total weight of the assumed lumped deposits in the array is approximately equal to the actual weight of the distributed deposit. Accuracies of about $\pm 50 \%$ are obtained using this method.

\section{UNCERTAINTIES IN WEIGHT ESTIMATES}

\section{Distance Error}

The uncertainty in the location of the effective center of a deposit will depend on how well the neutron flux is known at the various positions of the probe in the preliminary survey, but will be modified by knowledge of the structure and geometrical properties of the equipment being monitored. For example, a compact deposit in a valve might be located on the inner wall of the body or on the bellows seal. In a particular case, one of these locations might be favored or eliminated as determined by the circumstances. To some extent, then, each case becomes a unique problem and it is often possible to determine spatial limits for the region in which the deposit could be. If the flux measurements indicate the effective center to be at a certain point within the valve, the structure of the valve might limit the possibility of locating the deposit to within some certain distance from this position. The distance from the effective center to the probe position during 
the final counting might, for example, be expressed as 2 feet \pm 3 inches. Then limits on the value of the estimated weight could be determined using distances of 21 inches and 27 inches. The spread of these limits of the estimated weight would then be increased by consideration of other sources of error.

\section{Assay Error}

Often the assay of the uranium at a particular process point will have changed several per cent during the period of formation of a deposit. Thus, an old deposit would probably contain materials having a range of assay values. Calculations of weight should then be made for the smallest and largest probable assay values. For these calculations a fixed distance value is used: that of the most probable location for the effective center.

\section{Statistical Error}

A sufficient number of events should be counted so that the statistical error is small compared to the unavoidable uncertainty in distance. This error may be conveniently expressed by saying that if $n$ events are counted, repetitions of the counting for the same duration will show $\mathrm{n} \pm \sqrt{\mathrm{n}}$ events approximately two times out of three. This rule is satisfactory for these purposes if at least 100 events are counted. For 100 events, a $\pm 10 \%$ error may be expected; for 1000 events, the error at the 67 per cent confidence level would be about $\pm 3 \%$. Since this error must be applied to both gross and background counts, the total error would be 6 per cent if 1000 events are counted for each measurement. In the use of the neutron counter for deposit weight estimation, it is desirable to accumulate at least 1000 events in all counts, and this was done in the cases listed in the next section of this report.

\section{Total Error}

Sources of error other than statistical or distance and assay uncertainties may exist; for example, neutron flux attenuation and neutron reflection. No general method of estimation of such errors can be given; these are best avoided as far as possible by keeping offensive materials out of the vicinity of equipment being monitored. Fortunately, this is rarely difficult.

A rigorous treatment of errors is laborious and because of the large uncertainties inherent in this work (25\% to 50\%) a simple approximation is desirable. A satisfactory error estimate may be obtained by summing the distance and statistical errors calculated in the manner discussed. The assay of the deposit is usually known between limits and the best value of the estimated weight may be altered to conform to the limits of the assay value. 
TABLE II

EXAMPIES OF URANIUM DEPOSITS SURVEYED WITH THE ORGDP NEUTRON MONITOR

\begin{tabular}{|c|c|c|c|c|c|c|c|c|}
\hline \multirow{2}{*}{\begin{tabular}{|c|} 
Type \\
of \\
Equipment
\end{tabular}} & \multicolumn{2}{|c|}{ Form of Deposit } & \multicolumn{2}{|c|}{$\begin{array}{c}\text { Assay, } \\
\text { Percent of U-235 }\end{array}$} & \multicolumn{3}{|c|}{$\begin{array}{c}\text { Estimated Weight, } \\
\text { pounds }\end{array}$} & \multirow{2}{*}{$\begin{array}{c}\text { Recovered } \\
\text { Weight, } \\
\text { pounds }\end{array}$} \\
\hline & Geometrical & Chemical & Estimated & Recovered & LOW & Best & High & \\
\hline Valve & Distributed & $\mathrm{UO}_{2} \mathrm{~F}_{2}$ & 37 & 33 & 3.3 & 5.0 & 6.7 & 3.4 \\
\hline Valve & Compact & $\mathrm{UO}_{2} \mathrm{~F}_{2}$ & 37 & 36.5 & 2.6 & 3.5 & 5.0 & 3.63 \\
\hline Pipe & Compact & $\mathrm{UO}^{3} \mathrm{~F}^{3}$ & 92.5 & 94.0 & 0.017 & 0.035 & 0.22 & 0.026 \\
\hline Flanged Joint & Compact & $\mathrm{UO}_{2} \mathrm{~F}_{2}$ & 65.0 & 59.0 & 0.5 & 1.3 & 2.0 & 0.95 \\
\hline Valve & Compact & $\mathrm{UO}_{2} \mathrm{~F}_{2}$ & 50.0 & 20.0 & 1.0 & 1.5 & 2.2 & 1.82 \\
\hline Cold Trap & Distributed & $\mathrm{UO}_{2} \mathrm{~F}_{2}$ & 1.85 & 1.85 & 15. & - & 25.0 & 22.4 \\
\hline Flanged Joint & Compact & $\mathrm{UO}_{2} \mathrm{~F}_{2}$ & 36.0 & 31.4 & 0.25 & 0.5 & 1.0 & 0.35 \\
\hline Flanged Joint & Compact & $\mathrm{UO}_{2} \mathrm{~F}_{2}$ & 59.0 & 35.2 & 0.5 & 0.77 & 2.0 & 1.0 \\
\hline Pipe & No Deposit & U Daughters & 6.0 & - & - & 0 & - & - \\
\hline Flanged Joint & Semi-Compact & $\mathrm{UO}_{2} \mathrm{~F}_{2}$ & 70.0 & 56.8 & 1.5 & 2.1 & 3.0 & 2.5 \\
\hline Pipe* & Distributed & $\mathrm{UF}_{6}$ & 0.8 & 0.8 & - & 590.0 & - & $500 \pm 100$ \\
\hline Compressor & Diffuse & $\mathrm{UO}_{2} \mathrm{~F}_{2}$ & 8. & 6.8 & 5 . & 20. & 35. & 14.4 \\
\hline Valve** & Diffuse & $\mathrm{UO}_{2} \mathrm{~F}_{2}$ & $\left\{\begin{array}{l}62 \\
67\end{array}\right.$ & $\begin{array}{l}58.2 \\
58.2\end{array}$ & $\begin{array}{l}2 . \\
1.75\end{array}$ & $\begin{array}{l}3 . \\
2.7\end{array}$ & $\begin{array}{l}5 . \\
4 \cdot 3\end{array}$ & $\begin{array}{l}0.74 \\
0.74\end{array}$ \\
\hline $\begin{array}{l}\text { * An exper } \\
\text { accumula } \\
\text { weight e } \\
\text { weight i } \\
\text { recovere } \\
\text { pressure } \\
\text { * Two assa }\end{array}$ & $\begin{array}{l}\text { each sectior } \\
\text { in gaseous } \\
\text { rise in the } \\
\text { estimates }\end{array}$ & $\begin{array}{l}\text { allowing for } \\
\text { ceiving by heating } \\
\text { ceiving of the } \\
\text { e made of }\end{array}$ & pipe. Th & ns from a & $\begin{array}{l}\text { cent } \mathrm{s} \\
\text { ight } \mathrm{w}\end{array}$ & $\begin{array}{l}\text { 1ons ar } \\
\text { ections } \\
\text { as calc }\end{array}$ & $\begin{array}{l}\text { calch } \\
\text { The } \\
\text { lated }\end{array}$ & $\begin{array}{l}\text { UF } 6 \text { was } \\
\text { ion. The } \\
\text { ting the } \\
\text { terial was } \\
\text { om the }\end{array}$ \\
\hline
\end{tabular}




\section{EXAMPIES OF DEPOSIT WEIGHT ESTIMATES}

In table II (page 18) are listed some of the uranium deposits monitored with the neutron counter. The methods of estimation described in this report, as intended, have always yielded an upper limit value of the estimated weight in excess of the measured weight of the recovered material.

\section{ACKINOWLEDGEMENTS}

Preliminary investigations establishing the feasibility of developing the neutron monitor were made with the cooperation of $B$. J. Bogardus. Packaging of the electronic circuitry was done by G. B. Seaborn, who also assisted in adapting the circuit elements to the instrument. W. O. Gentry assisted in making field measurements with the monitor leading to the development of operating techniques.

\section{BIBLIOGRAPHY}

1. National Bureau of Standards Handbook 75, 1961, p. 62 .

2. Roberts, J.H., Neutron Yields of Several Light Elements Bombarded with Polonium Alpha Particles, The University of Chicago, N.D., Declassified January 7, 1947. (MDDC-731) 


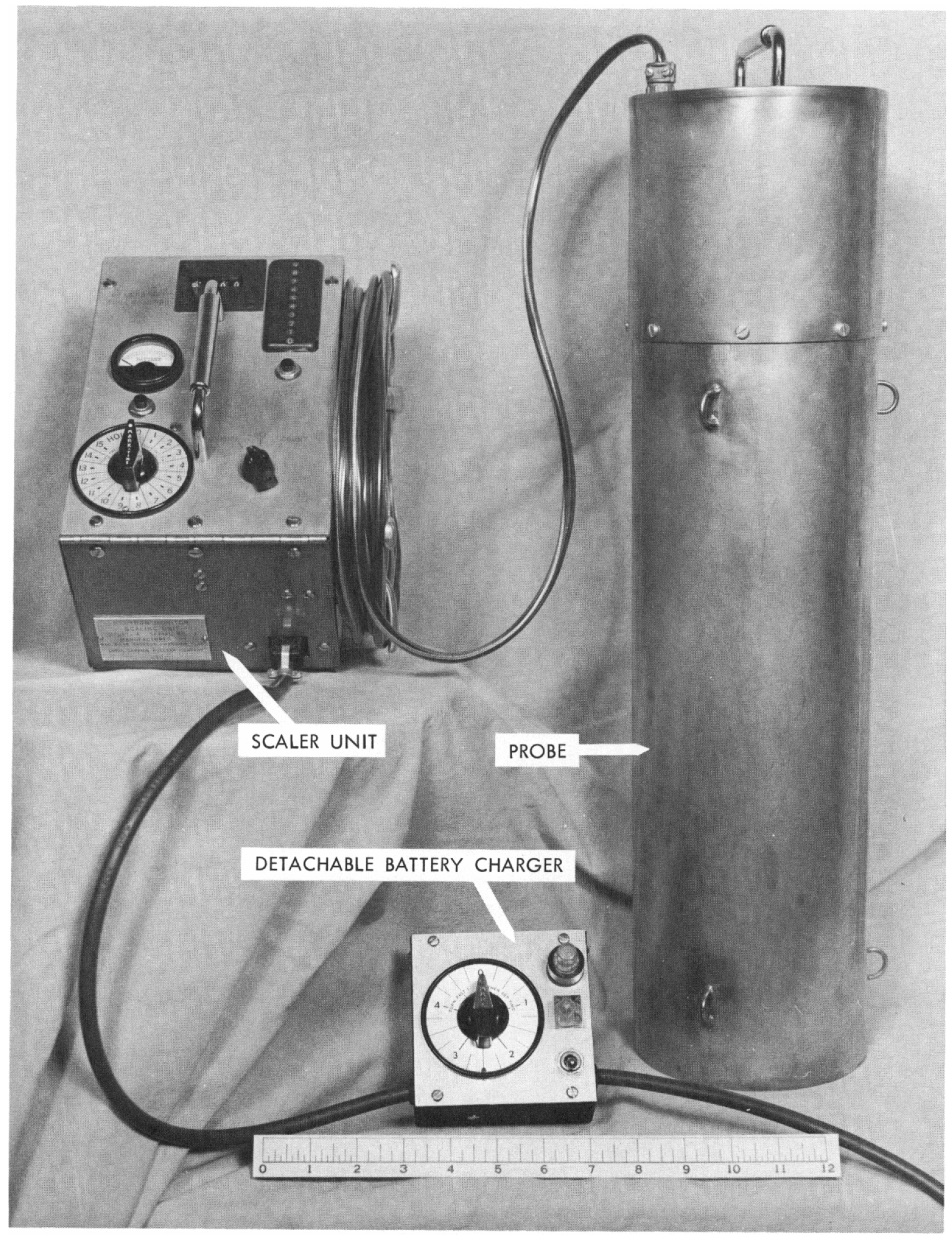

Figure 1

NEUTRON MONITOR FOR MEASURING URANIUM DEPOSITS 


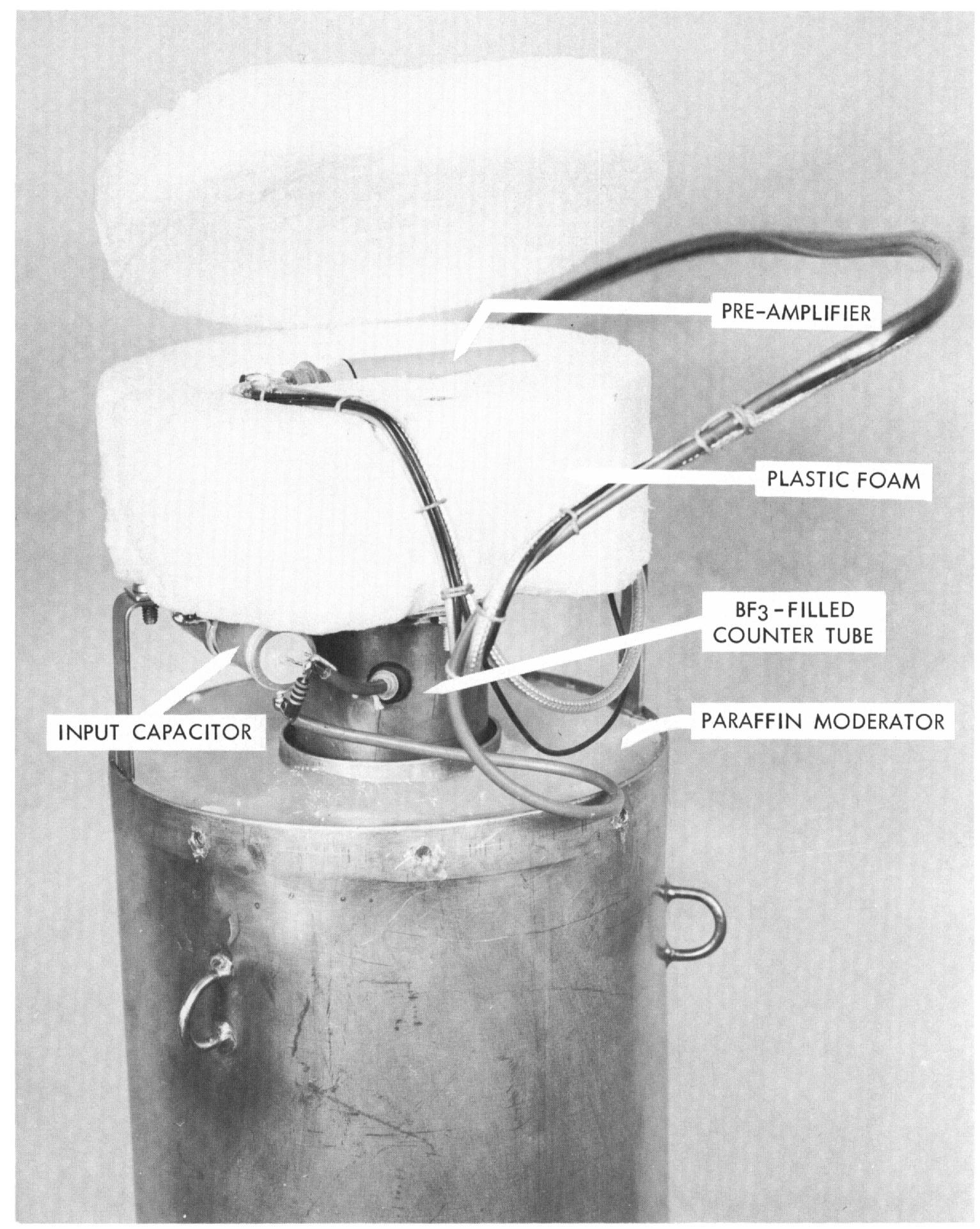

Figure 2

NEUTRON MONITOR PROBE WITH COVER REMOVED 

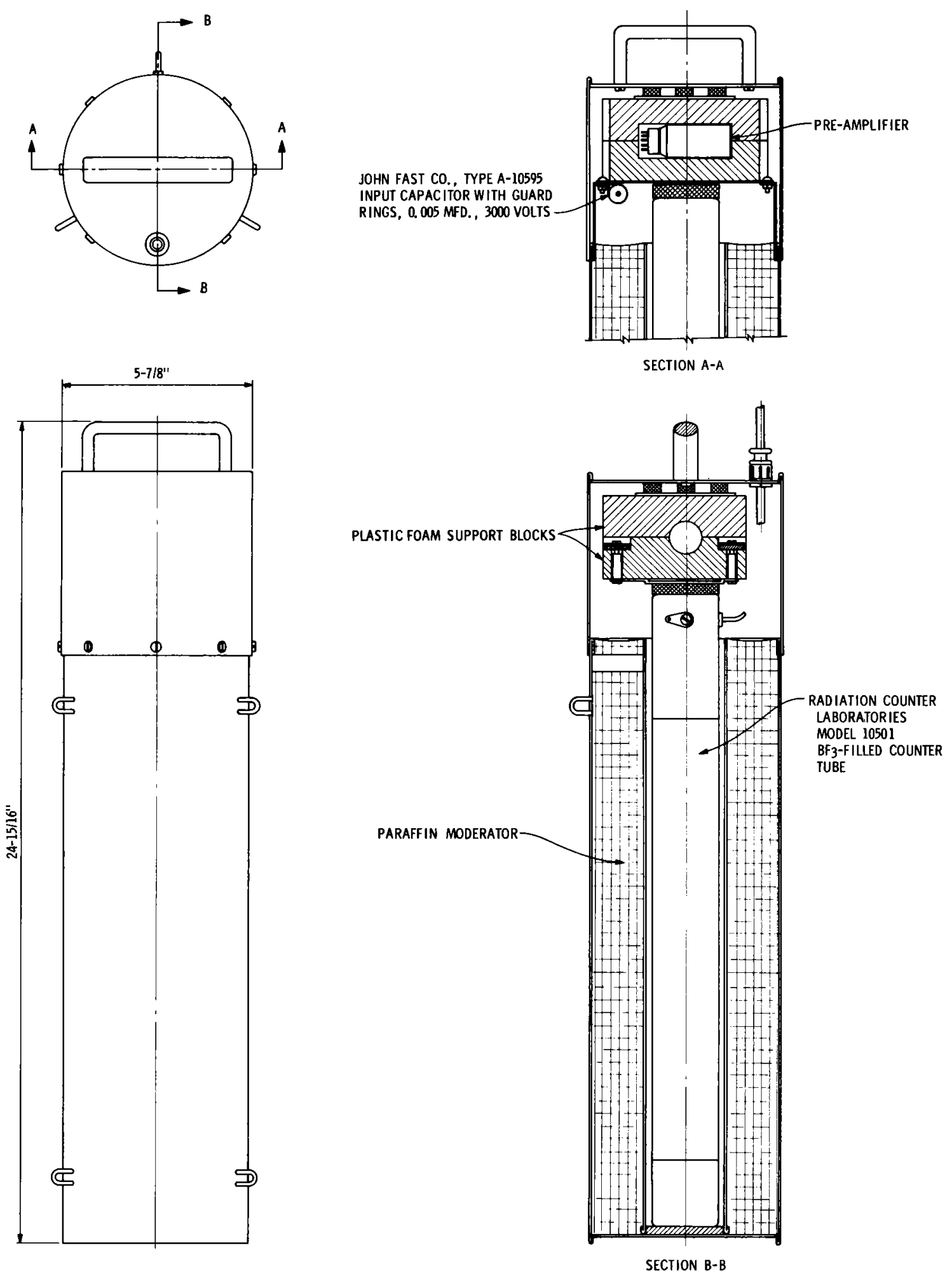

Figure 3

NEUTRON MONITOR PROBE ASSEMBLY 


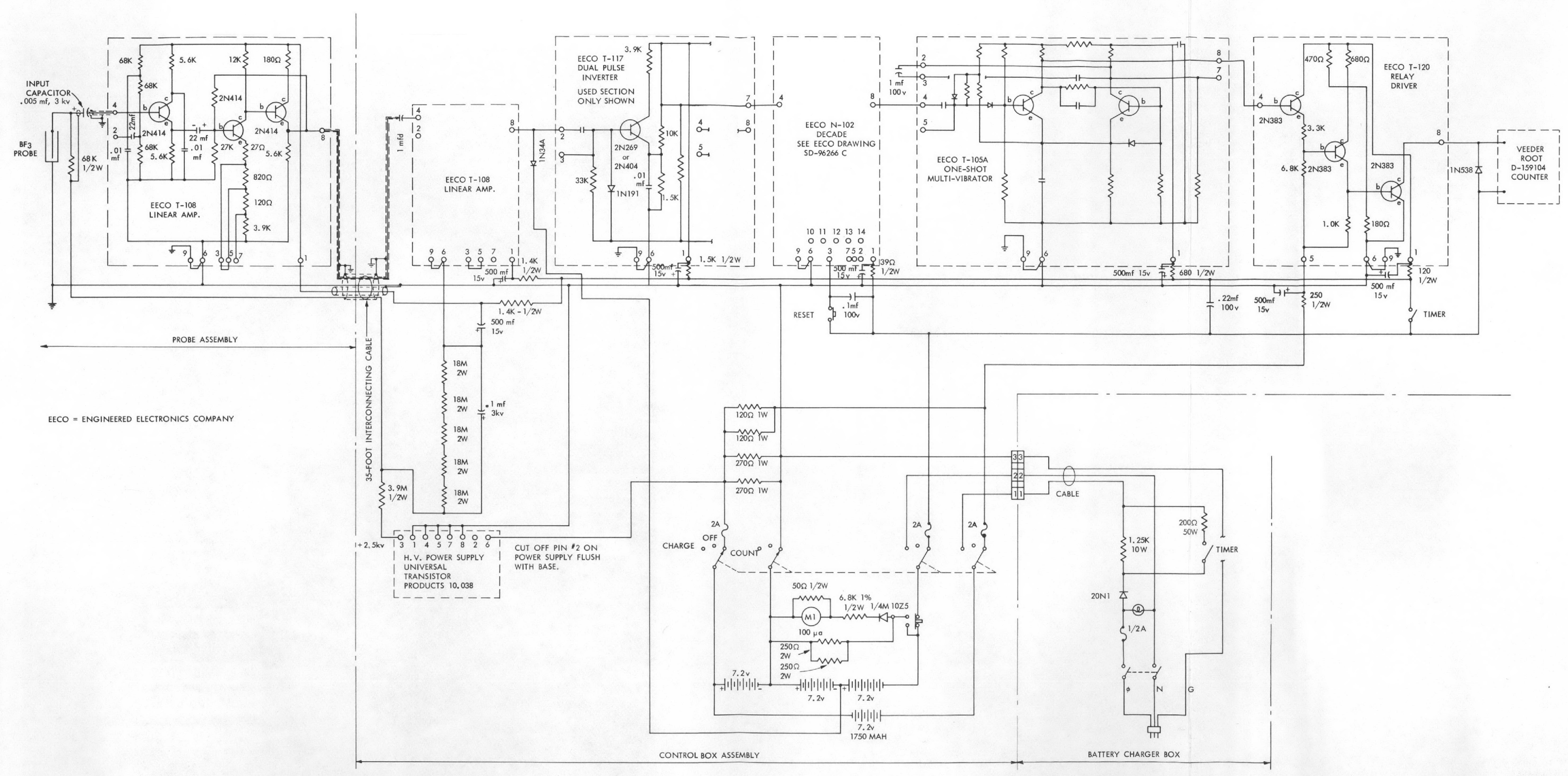

Figure 4

CIRCUIT DIAGRAM OF NEUTRON MONITOR 


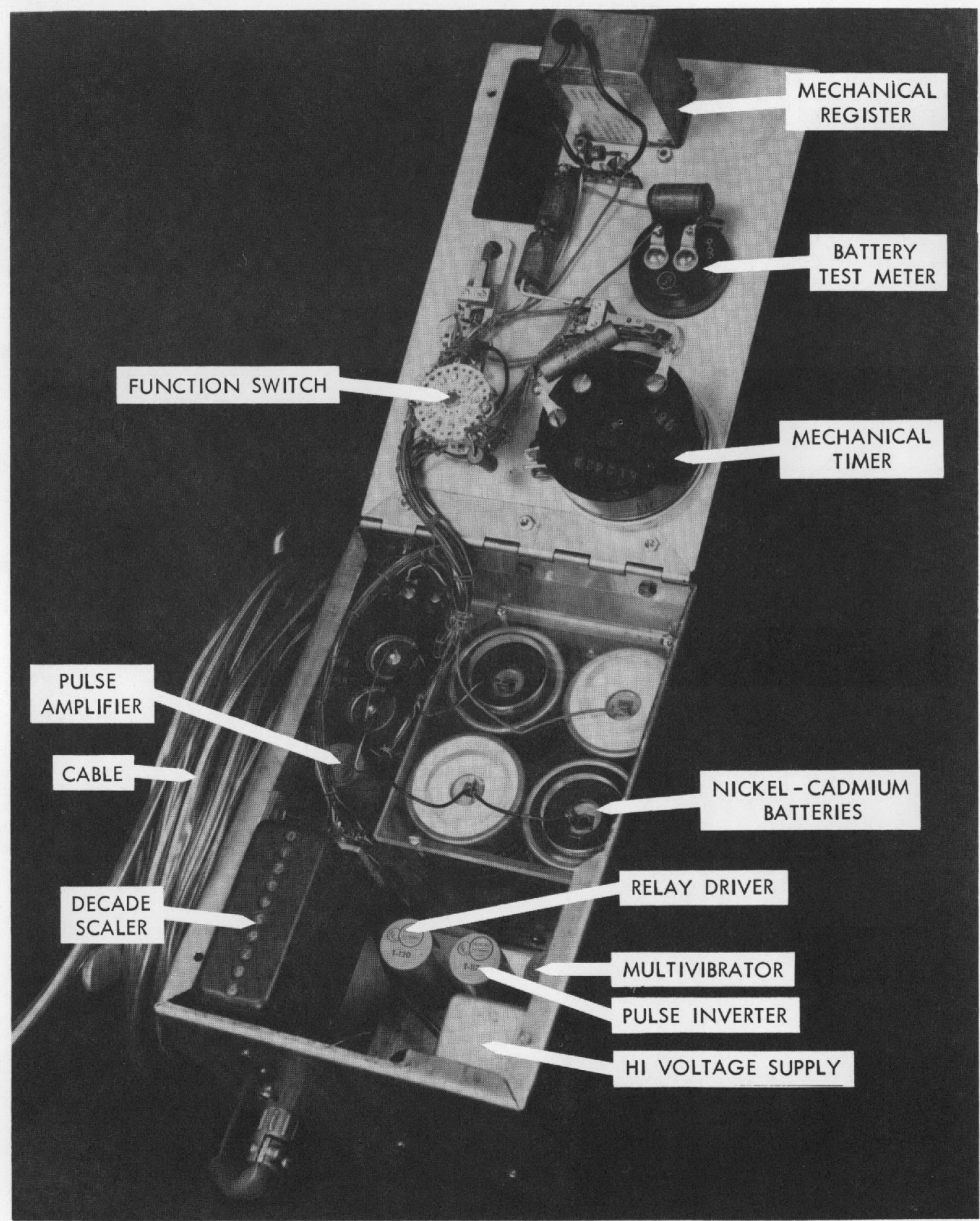

Figure 5

SCALER UNIT WITH COVER REMOVED 


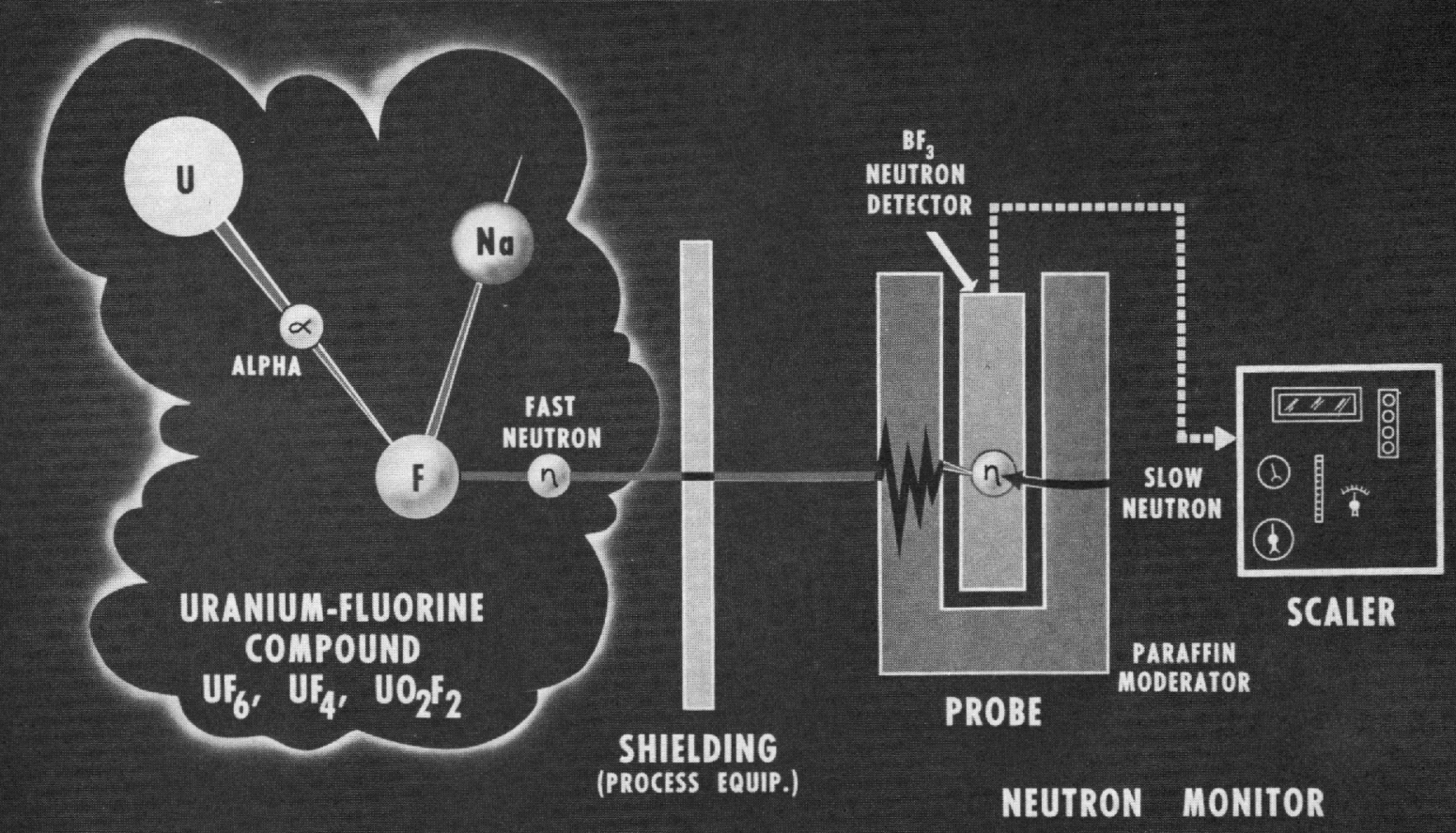

Figure 6

FORMATION AND COUNTING OF NEUTRONS

FROM URANIUM-FLUORINE COMPOUNDS 


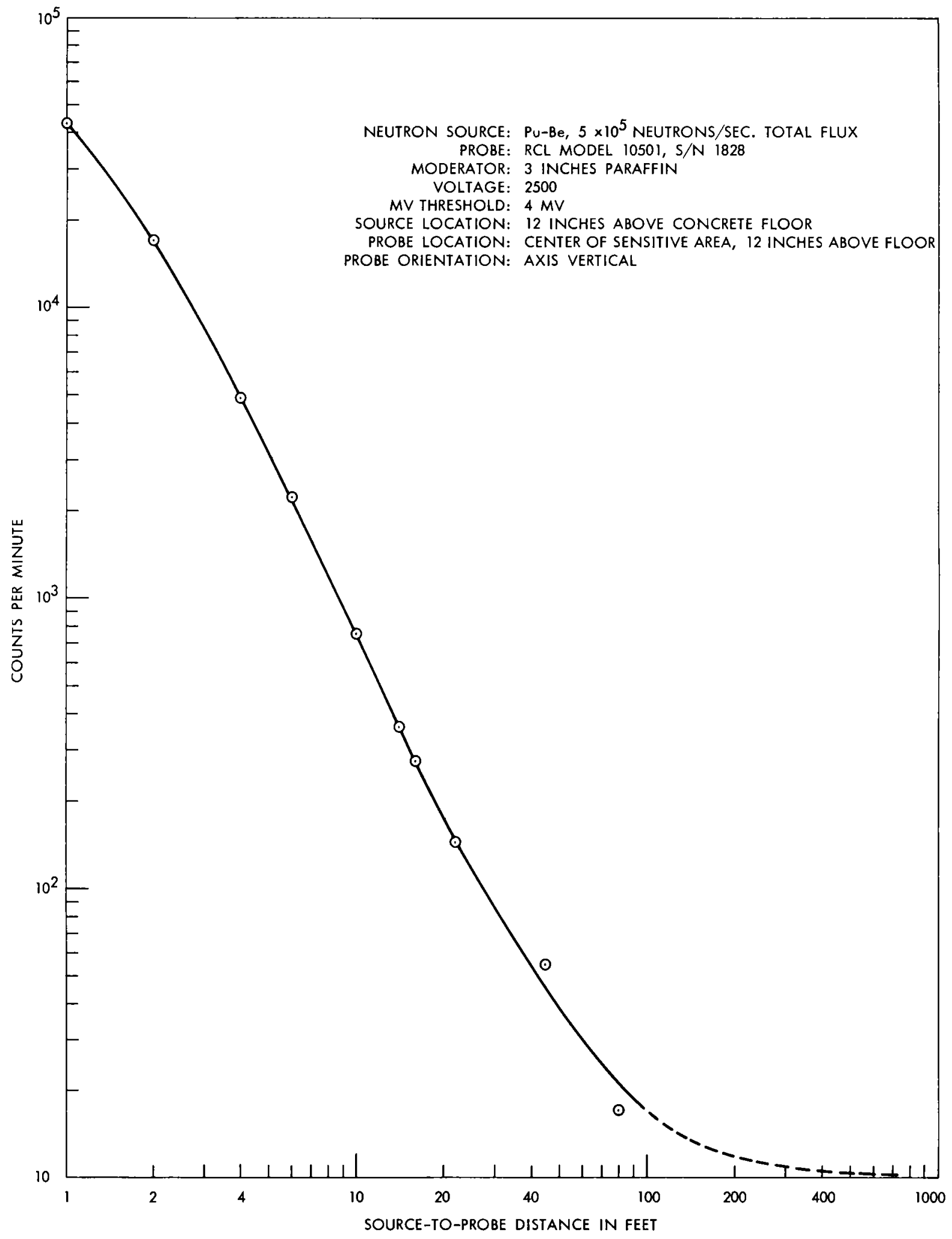

Figure 7

MONITOR RESPONSE AS A FUNCTION OF DISTANCE 


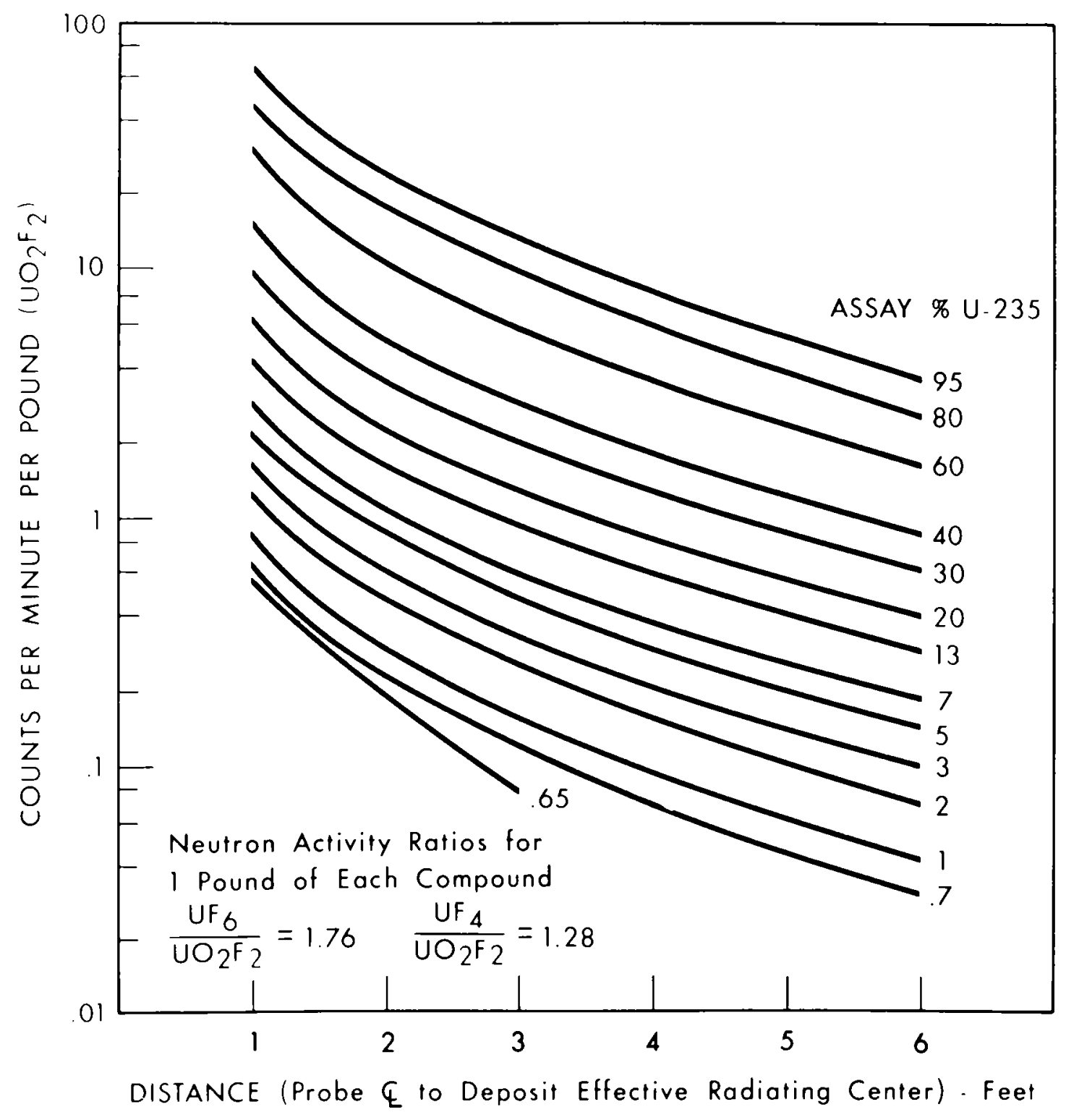

Figure 8

NEUTRON MONITOR CALIBRATION FOR UO ${ }_{2} \mathrm{~F}_{2}$ 


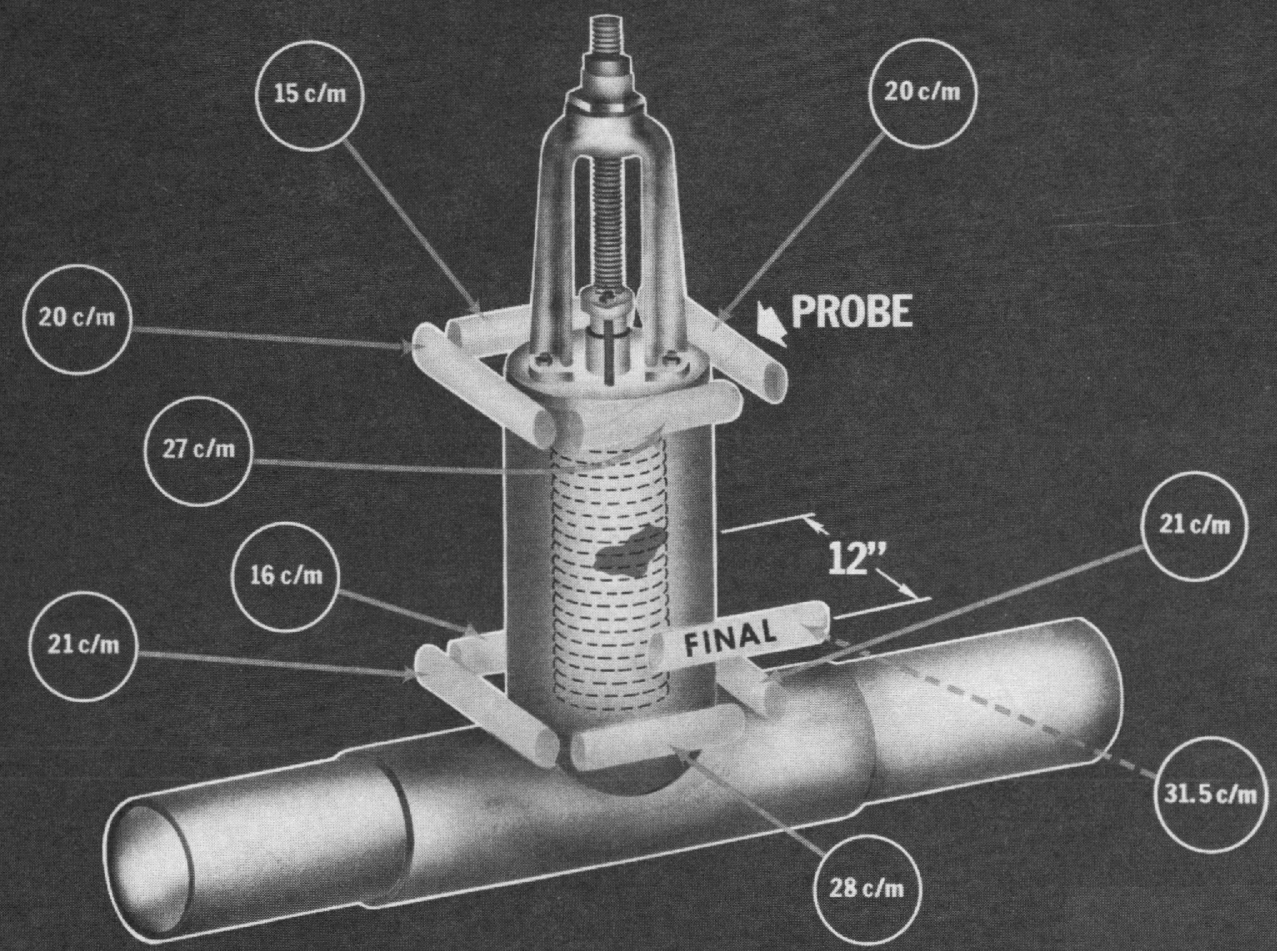

CALCULATED WEIGHT $=3$ LBS. $\mathrm{UO}_{2} \mathrm{~F}_{2}$ of $30 \%$ ASSAY

Figure 9

METHOD OF DETERMINING WEIGHTS OF COMPACT DEPOSITS 

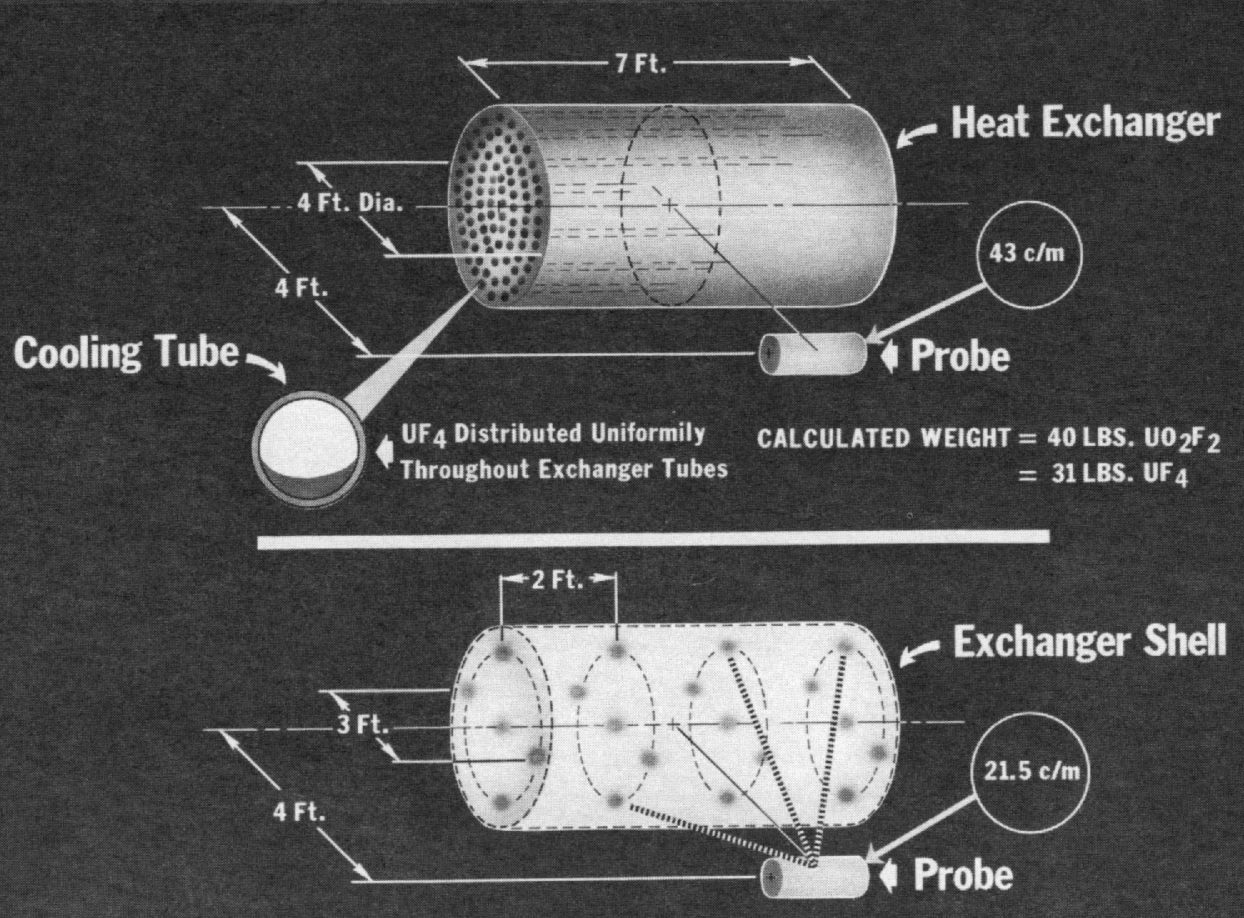

Assume Twenty Spheres of $\mathrm{UO}_{2} \mathrm{~F}_{2}$ in a Mock Distribution for Heat Exchanger Above Calculate Individual Neutron Flux for Each Sphere at its Distance from the Probe

Figure 10

MOCK DISTRIBUTION METHOD FOR DETERMINING WEIGHTS OF DISTRIBUTED DEPOSITS 


